\title{
Hydatidosis as a major cause of liver condemnation among parasitic diseases in goats and sheep in Keren slaughterhouse, Anseba zone, Eritrea
}

\author{
Michael K. Ghebremariam ${ }^{1,3}$, Menghistab G.Debesai ${ }^{2}$, D. Sanjay ${ }^{1}$ and A. P. Basharat ${ }^{1}$ \\ 1. Department of Veterinary Sciences, Hamelmalo Agricultural College, Eritrea, North-East Africa; 2. Department of \\ Agricultural Economics, Hamelmalo Agricultural College, Eritrea, North-East Africa; 3. Department of Infectious Diseases \\ and Immunology, Faculty of Veterinary Medicine, Utrecht University, Utrecht, The Netherlands \\ Corresponding author: Michael K. Ghebremariam, email: michaelvet@yahoo.com
}

Received: 21-12-2013, Revised: 17-03-2014, Accepted: 26-03-2014, Published online: 24-04-2014

doi: 10.14202/vetworld.2014.266-270 How to cite this article: Ghebremariam MK, Debesai MG, Sanjay D and Basharat AP (2014) Hydatidosis as a major cause of liver condemnation among parasitic diseases in goats and sheep in Keren slaughterhouse, Anseba zone, Eritrea, Veterinary World 7(4): 266-270.

\begin{abstract}
Aim: To find out the prevalence of hydatidosis and the number of livers condemned due to this disease using retrospective data from municipal slaughterhouse in Keren, Eritrea.

Materials and Methods: A retrospective data of ten years (1999 to 2008) on slaughtered goats and sheep was collected from Keren Municipal slaughterhouse, Anseba Zone of Eritrea. The data was analyzed for the prevalence of hydatidosis and the number of livers condemned. Besides, condemned livers from sheep and goats due to the presence of hydatid cysts were collected (September to December, 2008, and from March to July, 2009) for gross examination and microscopic pathology.
\end{abstract}

Result: Our findings indicated that among the parasitic diseases encountered in the slaughtered animals, hydatid cysts were the most prevalent ones.

Conclusion: This study has depicted that the major contributor for liver condemnation was hydatidosis. Moreover, the study has shown that the trend of the prevalence of hydatidosis is increasing and this warrants immediate intervention for its control.

Keywords: Eritrea, goat, hydatidosis, liver, sheep, slaughterhouse.

\section{I ntroduction}

Livestock is a very important component in the agricultural production system in Eritrea. It plays a significant role in the livelihood and the GDP of the country [1]. Sheep and goats are vital components of the agricultural system of the country. However, they are affected by hydatidosis which has both economic and zoonotic importance [2-4]. In Eritrea, because of the unpredictable and low rainfall, cropping is often at risk in the arid and semi-arid areas. Hence, sheep and goat production under pastoral system is a very good way of compensating the failing crop in most parts of the country. Moreover, this type of production system could be a reliable potential source of livelihood provided that effective disease control measures are undertaken. Among the many constraints, disease and parasites are of major importance. According to the Ministry of Agriculture's Annual reports (1999-2003) [5], in Eritrea, 70-80 \% of the health problems in small ruminants were estimated to be due to internal and external parasite infestation.

Hydatidosis (Echinococcosis) is an important public health problem in many parts of the world, especially in rural areas where sheep, goats and cattle are raised $[2,6]$. The greatest prevalence of cystic

Copyright: The authors. This article is an open access article licensed under the terms of the Creative Commons Attribution License (http://creativecommons.org/licenses/by/2.0) which permits unrestricted use, distribution and reproduction in any medium, provided the work is properly cited. echinococcosis in human and animal hosts is found in countries of the temperate zones, including several parts of Eurasia (the Mediterranean regions, southern and central parts of Russia, central Asia, China), Australia, some parts of America (especially South America) and north and east Africa. Echinococcosis is currently considered an endemic zoonotic disease in the African region [7-9].

Thus, it is imperative to have data regarding the major diseases prevalent in a given place in order to take effective control measures. Besides, it is also important to find out the diseases shared by both animals and humans. For this purpose, slaughterhouses are a very good data source for both the diseases of public health and economic importance. Slaughterhouse disease surveillance is considered to be an important method for confirming diagnosis, diseases control and eradication campaigns worldwide [10].

In the current study, disease surveillance in a slaughterhouse was considered an alternative method to investigate the parasitic disease of economic and zoonotic importance. The study was conducted in sheep and goats slaughtered at Keren slaughterhouse in Anseba Zone, Eritrea. Keren is the main town of Anseba Zone, located $90 \mathrm{kms}$, North-West of Asmara, the capital city of Eritrea, and lies about 1800 meters above sea level. The purpose of the study was to find out the presence of hydatid cysts and the number of organs condemned due to the cysts. 
Table-1: Number of slaughtered animals, condemned number of livers, and the annual prevalence of Hydatidosis at Keren Slaughterhouse (1999-2008).

\begin{tabular}{ccccc}
\hline Sr. No. & Year & Slaughtered animals & Condemned livers due to hydatidosis & Prevalence \% \\
\hline 1 & 1999 & 24171 & 362 & 1.5 \\
2 & 2000 & 24111 & 500 & 2.1 \\
3 & 2001 & 24817 & 818 & 3.3 \\
4 & 2002 & 18909 & 569 & 3.0 \\
5 & 2003 & 17473 & 565 & 3.2 \\
6 & 2004 & 12904 & 652 & 5.1 \\
7 & 2005 & 7048 & 304 & 4.3 \\
8 & 2006 & 8910 & 491 & 5.5 \\
9 & 2007 & 10208 & 491 & 4.8 \\
10 & 2008 & 7170 & 592 & 8.3 \\
\hline
\end{tabular}

\section{Materials and Methods}

A retrospective data of ten years (1999 through 2008) was collected from Keren slaughterhouse, Anseba Zone, Eritrea. Moreover, condemned organs were collected on a weekly basis for gross pathology and microscopic examination (September - December, 2008, and from March -July, 2009). The data was collected to find out the prevalence of Hydatidosis and the number of organs condemned due to the presence of Hydatid cysts. Besides, the data collection has considered the number of animals slaughtered during the study period (1999-2008).

Statistical analysis: The collected data was analyzed using statistical packages such as SPSS version 11 software and Microsoft excel.

A linear regression model was employed to analyze the trend of slaughtered animals and condemned organs throughout the record period. To validate the significance of the coefficients that explain the rate of change per unit time (year) or trend, the standard errors (SE) and t-statistics (t-test) were used. Means, standard deviations, ranges and percentages were also used when necessary.

Assessment of trend and prevalence of the parasitic diseases: The total number of slaughtered animals (TNA) was linearly regressed against time (T) in order to visualize the trend (average yearly increase or decrease) in the number of animals slaughtered as follows.

$$
\begin{aligned}
\mathrm{TNA} & =\mathrm{f}(\mathrm{T}) \\
\mathrm{TNA} & =\beta_{1}+\beta_{2} \mathrm{~T} \ldots \ldots \ldots . .[E q .1] a
\end{aligned}
$$

The slope coefficient $\left(\beta_{2}\right)$ gives an average estimate of the change in the number of animals slaughtered year by year [11].

Once more, the total number of organs (liver in particular) condemned (TNO) was also regressed linearly against time (T) to identify the trend (average yearly increase or decrease) in the number of condemned (livers) organs as follows:

$$
\begin{aligned}
& \mathrm{TNO}=\mathrm{f}(\mathrm{T}) \\
& \left.\mathrm{TNO}=\alpha_{1+} \alpha_{2} \mathrm{~T} \ldots \ldots . \ldots . \text { [eq. } 2\right] a
\end{aligned}
$$

The slope coefficient $\alpha_{2}$ indicates an average estimate of the trend in the number of organs (liver) condemned each year due to Hydatidosis [11]. By comparing [Eq.1]a, the trend of animals slaughtered, and $[E q .2] a$, the trend of organs condemned; the prevalence of parasitic diseases (such as Hydatidosis) can be estimated. The average prevalence $(\mathrm{Pr})$ of the parasitic diseases (Hydatidosis), as a representative for each year, can be expressed as the proportion or percentage of the condemned organs (TNO) resulting from Hydatidosis to the total number of animals slaughtered [12].

$$
\mathrm{Pr}=(\mathrm{TNO} / \mathrm{TNA}) \times 100 \%
$$

This study has emphasized on the number of livers condemned due to Hydatidosis.

To show the trend of prevalence throughout the record period, annual prevalence rate was also calculated.

\section{Results}

During the ten years of record in the slaughterhouse of Keren town, a total of 155,721 animals of which $92 \%$ goats, $7 \%$ Cattle and 1\% sheep were slaughtered. The sources of the slaughtered animals were the surrounding sub-zones with similar climatic condition to Keren town. High number of slaughter was recorded in the year 2001. The annual number of animals slaughtered on average was 15,572 with standard deviation $\pm 7,231$, and range 7,048 to 24,817 . Regression of total number of animals slaughtered (TNA) on time period (T) depicted that on average there was an annual decrease in the number of animals slaughtered by 2,243 which is statistically significant at $95 \%$ confidence interval. The linear regression is presented as follows:

$$
\begin{aligned}
& \text { TNA }=27,906-2,242.53 \mathrm{~T} \ldots . .[E q .1] b \\
& \mathrm{Se}=(1,802.8) \quad(290.55) \\
& \mathrm{t}=(15.48)^{*} \quad(-7.72)^{*} \\
& \mathrm{r}^{2}=0.87
\end{aligned}
$$

From the linear regression equation, the value of $\beta_{2}$ is $-2,242.53$ indicating that on average the number of animals slaughtered decreased by that number from year to year. The coefficient of determination $r^{2}$ shows that $87 \%$ of the variation in the number of slaughters is due to variation in time (year).

Figure-1 shows the average annual number of animals slaughtered decreased from year to year.

The total number of livers condemned due to Hydatidosis during the ten years was 5,345. The annual mean and standard deviation respectively were estimated to be 534 and 144, with a range of 304-818. High numbers of condemned organs were found in the year 2001.

The total number of organs (livers) condemned (TNO) was once more regressed against time (year) 


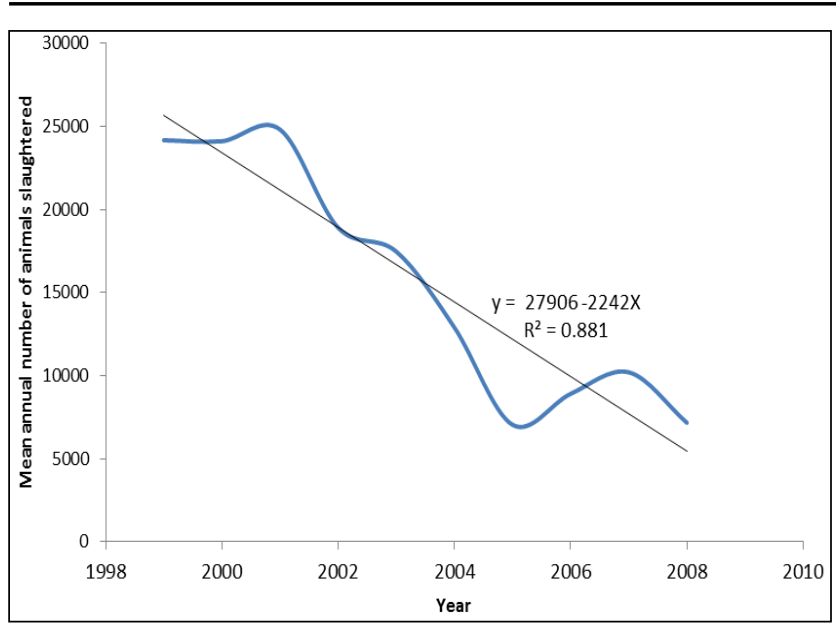

Figure-1: Trend of the number of animals slaughtered in ten years time (1998-2010).

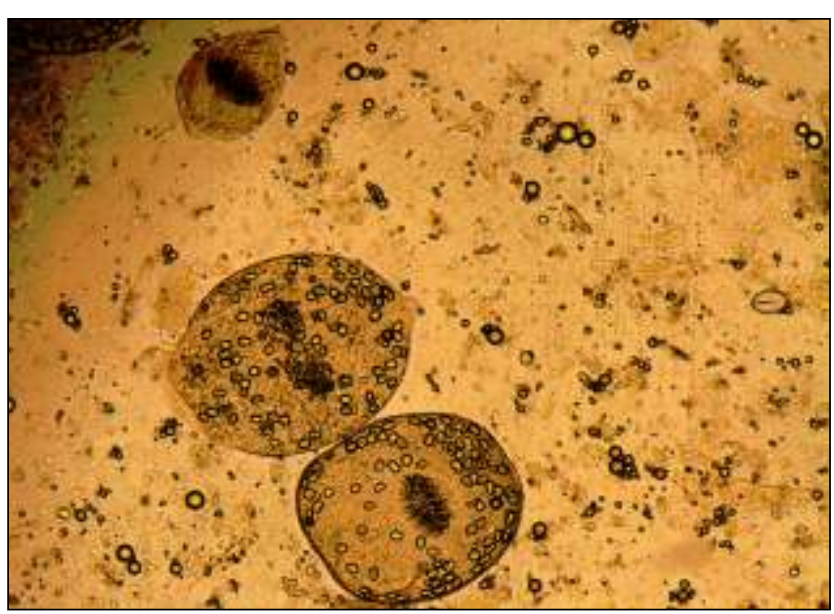

Figure-3: Hydatid sand in hydatid fluid collected from hydatid cyst.

(T). This depicted that on average only two organs (liver) less, which is statistically insignificant, were condemned than the preceding year.

$$
\begin{aligned}
& \mathrm{TNO}=545.6-2.04 \mathrm{~T} \ldots \ldots \ldots . .[E q .2] b \\
& \mathrm{Se}=(104.48)(16.840) \\
& \mathrm{t}=(5.22) \quad(-0.12)
\end{aligned}
$$

Normally, for a decreasing number of animals slaughtered each year and hence less number of animals tested year by year, one expects less number of organs condemned. Neverthless, the finding indicates a slight increase in the number of organs condemned even if the tested animals were decreasing in number. This implies logically an increasing number of the condemnation of affected organs and hence an increasing trend or prevelance of the disease throughout the tested period of ten years. Moreover, this trend also indicates that no attempt has been made to control hydatidosis in the country.

Table-1 and Figure- 2 depicts that the prevalence of hydatidosis increased from year to year whereas the number of animals slaughtered (tested) decreased.

\section{Gross pathology and microscopic examination}

Gross pathology: Gross pathology of the collected organs demonstrated typical lesions with fluid filled cysts on the livers. Upon incision of the fluid filled

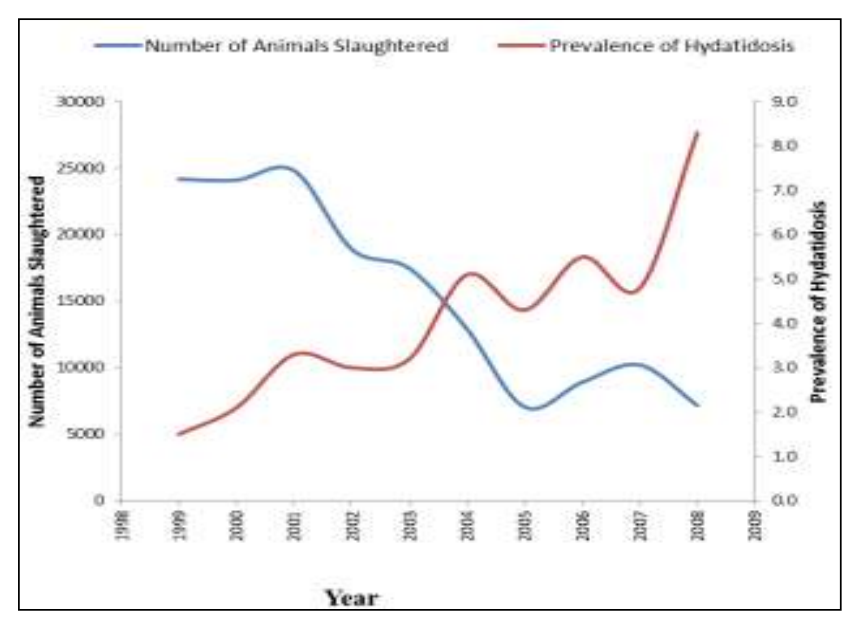

Figure-2: Trend of the number of animals slaughtered and the prevalence of Hydatidosis in ten years.

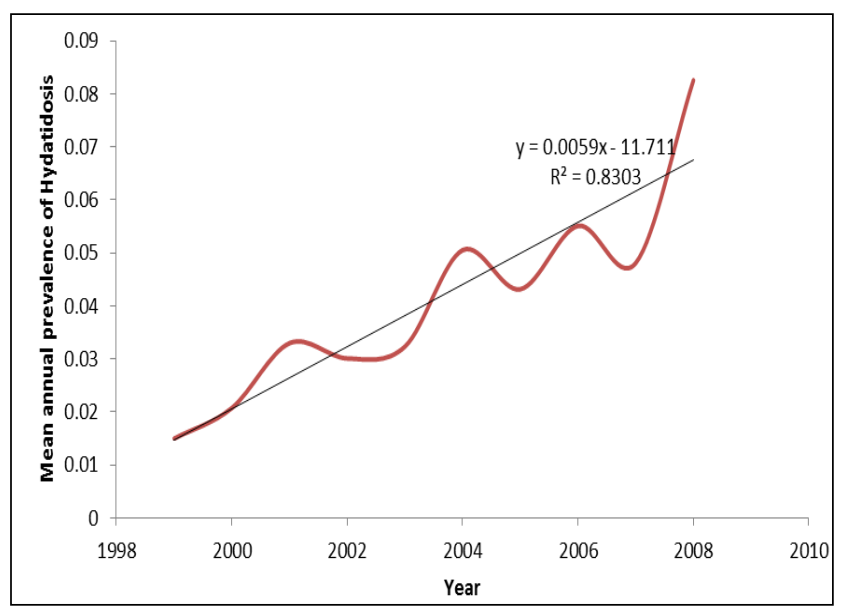

Figure-4: An increasing trend of the prevalence of Hydatidosis in ten years (1999-2008).

cysts, three distinct layers (structures) were demonstrated, namely; an outer pericyst, a middle laminated membrane, and an inner germinal layer [13].

Microscopic examination: Fine needle aspiration from the collected hydatid cysts has demonstrated clearly the presence of hydatid sands (Figure-3).

\section{Discussion}

Echinococcosis, which is often referred to as hydatid disease or echinococcal disease, is a parasitic disease that affects both humans and other mammals, such as sheep, dogs, rodents and horses [14]. The worldwide incidence and prevalence of cystic echinococcosis has reduced considerably over the past several decades. Nevertheless, infection with Echinococcus granulosus remains a major public health issue in several countries and regions due to lack of control programmes, economic problems and lack of resources [15].

In the present study, the average prevalence expressed as a proportion of the number of livers condemned due to Hydatidosis to the total number of slaughtered animals was $3.4 \%$. This prevalence rate is not very high when compared with other studies [16]. Nevertheless, it is worth noting that pathological lesion 
of the affected livers causes considerable loss to affected organs (livers) due to partial or complete condemnation of the affected parts. One of the major limitations of the present study was the absence of the registration of ages of the animals in the slaughterhouse. When undertaking surveillance work with $E$. granulosus in intermediate hosts, it is very crucial that data are stratified and reported according to the age of animals slaughtered. Prevalence rates are strongly age dependent and Hydatidosis is more common in aged animals [17-20]. But considering the prevalence rates observed in our study, it can be assumed that many young animals were being slaughtered during the record time. Thus, the true situation of hydatidosis might have been under-represented. The presence of hydatid cysts was reported to be relatively higher in lungs than in liver [16, 21, 22]. However, the current study has found that liver is the organ that is more frequently affected than the lungs. This finding is in agreement with the studies conducted somewhere else in Kenya [23], Turkey [18] and Egypt [24].

In this study it was difficult to precisely trace back the geographical origins of all animals slaughtered due to lack of reliable animal identification method. Therefore, relating the findings of the study to a precise localities is difficult. However, it is known that almost all the animals slaughtered came from the traditional livestock production system. In the traditional livestock husbandry system keeping dogs along with livestock is a very common practice. Echinococcus granulosis is reported to be a common finding in dogs from all subSaharan countries [4]. Thus, the presence of nomadic or semi-nomadic goat and sheep population that represent the intermediate host of the parasite, and their close contact with the final host, the dog, might increase the risk of transmission of infection to humans. Camel and cattle are also reported to be the principal intermediate hosts of the disease [25]. However, in regards to which of the intermediate hosts are crucial in disseminating the disease seems to vary from study to study [26].

The current study has pointed out the fact that Hydatidosis is a very serious zoonotic parasitic disease which currently is prevalent in Eritrea. Besides, this study has depicted that the prevalence of the disease is increasing from time to time (Figure-4). Similar increasing trend in the prevalence of hydatidosis was also reported in Kenya [23]. By and large, though the worldwide incidence and prevalence of cystic echinococcosis has reduced over the past several decades, it still remains a major public health issue in several countries and regions [15].

Therefore, in Eritrea, immediate intervention through deworming of dogs and treatment of affected animals is mandatory. It will also be wise to investigate the role of wildlife in harboring and transmitting hydatidosis to other susceptible animals [27]. The economic importance of hydatidosis was reported in recent studies conducted in slaughtered cattle in Ethiopia. In these studies annual economic loses of
30,202.64 USD in Wolaiyta Sodo and 138,202.64 USD in Hawassa, municipal abattoirs, in Southern Ethiopia, were reported, respectively [28, 29]. Moreover, a study conducted in slaughtered sheep and goats in Addis Ababa municipal abattoir indicated a total financial loss of 20,822.40 USD (270,691.34 Ethiopian Birr), mainly due to carcass weight loss and condemnation of organs [30]. These findings from neighboring Ethiopia might also be true in Eritrea, where similar livestock husbandry systems are practiced, though our study hasn't attempted to estimate the economic loses.

To control hydatidosis, apart from deworming of intermediate hosts, proper disposal of affected organs and offals, vaccination can also be considered in areas where there is a high prevalence of Hydatidosis. Recent findings have indicated that progress has been made in the development of an effective vaccine against infection with the larval stage of E. granulosus in sheep and cattle [17]. Experience of a country like Cyprus has shown the possibility of successful implementation of eradication programs of Echinococcosis [8]. It is worth mentioning that lack of control programs, resources, and economic problems are the major culprits that make E. granulosus to remain a public health and economic concern [15]. The public health issue requires a serious consideration in this country.

\section{Conclusion}

Hydatidosis is an important disease that leads to high liver condemnation in Keren municipal slaughterhouse, Eritrea. As this was the first slaughterhouse study of its kind for the region (Anseba region) that indicated the prevalence and economic significance of the disease, further study on the epidemiology of the disease, covering larger areas is required for establishment of an effective control program. Further studies need to be initiated at the definitive host (dog) level, so as to have a complete picture of the disease and to design appropriate control measures.

\section{Authors' contributions}

MKG: designed the study, gathered information, performed diagnosis of the slaughterhouse specimens on the basis of their gross pathology, and did the write up of the manuscript. SD: engaged in data collection and write up of the paper. MGD: analyzed the data and involved in the write up of the manuscript. BAP: did the parasitic examination, compiled the results and involved in the write up of the manuscript. All authors read and approved the final manuscript.

\section{Acknowledgements}

This study was fully funded by the Hamelmalo Agricultural College. The authors are grateful to the Dean and Associate Dean (Academic Affairs) of Hamelmalo Agricultural College, Eritrea, for their support during this study. The authors are also very thankful to the Municipal Slaughterhouse of Keren, particularly, to Mr. Yohanness, the senior meat inspector. 


\section{Competing interests}

The authors declare that they have no competing interests.

\section{References}

1. Ministry of Agriculture (2006) Country Report, Eritrea. In: $17^{\text {th }}$ Conference of the OIE Regional Commission for Africa. Asmara, Eritrea., 26 February - 1 March, 2007. p46-49.

2. Erbeto, K., Zewde G. and Kumsa B. (2010) Hydatidosis of sheep and goats slaughtered at Addis Ababa Abattoir: prevalence and risk factors. Trop Anim Health Prod. , 42 (5): 803-5.

3. Elshazly, A.M., Awad, S.E., Hegazy, M.A., Mohammed, K.A. and Morsy, T.A. (2007) Echonococcosis granulosis /hydatidosis an endemic zoonotic disease in Egypt. J.Egypt Soc Parasitol. 37(2):609-622.

4. Magambo, J., Njoroge, E and Zeyhle, E. (2006) Epidemiology and control of echinococcosis in sub-Saharan Africa. Parasitol Int., 55 (suppl):S193-195.

5. Ministry of Agriculture Annual Report (1999-2003) Asmara, Eritrea.

6. Kebede, W., Hagos, A., Girma, Z. and Lobago. F. (2009) Echonococcosis/hydatidosis: its prevalence, economic and public health significance in Tigray region, North Ethiopia. Trop Anim Health Prod. , 41(6): 865-871.

7. Grosso, G., Gruttadauria, S., Biondi. A., Marventano, S. and Mistretta, A. (2012) Worldwide epidemiology of liver hydatidosis including the Mediterranean area. World $J$ Gastroenterol., 18 (13): 1425-1437.

8. Dakkak, A. (2010) Echinococcosis: a severe threat in Mediterranean countries. Vet. Parasitol. 174(1-2): 2-11.

9. Thompson, R.C.A., McManus, D.P., (2001) Aetiology: parasites and life-cycles. In: Eckert, J., Gemmell, M., Meslin, F-X, Pawlowski, Z., editors. WHOI/OIE, Paris. Manual on echinococcosis in humans and animals: a public health problem of global concern. Geneva: World Organisation for Animal Health, p1-19.

10. Qudah. Al., Khalid, M. , Ahmad M., Majali. Al, and Obaidat.M.M. (2008) A study on pathological and Microbiological Conditions in Goats in slaughterhouses in Jordan. Asian J. Anim. Vet. Adv., 3(4):269-274.

11. Gujarati, D.N. (2004) Basic Econometrics. Fourth Edition. New York: McGraw-Hill.p125-158.

12. Swai, E. S. and Ulicky, E. (2009) An Evaluation of the economic losses Resulting from condemnation of cattle livers and losses of carcass weight due to Fasciolosis: a case study from Hai town Abattoir. Livest Res Rural Dev., 21.

13. Pedrosa. I., Saíz. A., Arrazola. J., Ferreirós. J., Pedrosa. C.S (2000) Hydatid disease: radiologic and pathologic features and complications. Radiographics, 20(3): 795-817.

14. Berger, S.A, Marr, J.S. (2006) Human Parasitic Diseases Sourcebook. Jones and Bartlett Publishers: Sudbury, Massachusetts. p166-169.

15. Eckert, J., Conraths, F. J. and Tackmann, K. (2000)
Echinococcosis: an emerging or re-emerging zoonosis? Int $J$ Parasitol., 30:1283-1294.

16. Sangaran, A. and Lalitha, John (2009) Prevalence of Hydatidosis in Sheep and Goats in and Around Chennai. Tamil Nadu J. Veterinary and Animal Science., 5 (5): 208210.

17. OIE Terrestrial Manual (2008) Echinococcosis/Hydatidosis. p175-189.

18. Ulutas, Esatgil, Meltem and Erkut Tüzer (2007) Prevalence of Hydatidosis in Slaughtered Animals in Thrace, Turkey. Türkiye Parazitoloji Dergisi., 31 (1): 41-45.

19. Lahmar, S., Chéhida, F.B., Pétavy, A.F., Hammou, A., Lahmar, J., Ghannay, A., Gharby, H.A. and Sarciron, M.E. (2007) Ultrasonographic screening for cystic echinococcosis in sheep in Tunisia. Vet Parasitol., 19 (1): 42-49.

20. Lahmar, S., Kilani, M., Torgerson, P.R. and Gemmell, M.A. (1999) Echinococcus granulosus larvae in the livers of sheep in Tunisia. Ann Trop Med Parasitol., 93(1): 75-81.

21. Koskei, P., Janitschke, K. and Feseha, G. (2011) Prevalence of Echinococcus granulosus in some selected sites of Ethiopia. East Afr. J. Public Health., 8(3): 170-175.

22. Pandey, V.S., Ouhelli, H. and Ouchtou, M. (1986) Hydatidosis in sheep, goats and dromedaries in Morocco. Ann Trop Med Parasitol., 80(5): 525-529.

23. Addy, F., Alakonya, A., Wamae, N., Magambo, J., Mbae, C., Mulinge, E., Zayhle, E., Wassermann, M., Kern, P. and Roming, T. (2012) Prevalence and diversity of cystic echinococcosis in livestock in maasailand, Kenya. Parasitol Res., 111 (6): 2289-2294.

24. Rahman, M.S., Sokkar, S.M, and Dahab, S. (1992) Comparative studies on hydatidosis in farm animals in Egypt. Dtsch Tierarztl Wochenschr., 99(11): 438-40.

25. Elmahdi, I.E., Ali, Q.M., Magzoub, M.M., Ibrahim, A.M., Saad, M.B. and Romig, T. (2004) Cystic echinococcosis of livestock and humans in central Sudan. Ann Trop Med Parasitol., 98(5): 473-479.

26. Haridy, F.M., Ibrahim, B.B. and Morsy, T.A. (2000) Sheepdog-man. The risk zoonotic cycle in hydatidosis. J Egypt Soc Parasitol., 30 (2): 423-429.

27. Gathura, P.B. and Kamiya, M. (1990) Echinococcosis in Kenya: transmission characteristics, incidence and control measures. Jpn J Vet Res., 38: 107-116.

28. Bekele, J. and Butako, B. (2011) Occurrence and financial loss assessment of cystic echinococcosis (hydatidosis) in cattle slaughtered at Wolyita Sodo municipal abattoir, Southern Ethiopia. Trop Anim Health Prod. 43(1): 221-228.

29. Regassa, F., Molla, A. and Bekele, F. (2010) Study on the prevalence of cystic hydatidosis and economic significance in cattle slaughtered at Hawassa Municipal abattoir, Ethiopia. Trop Anim Health Prod. 42(5): 977-984.

30. Getachew, H., Guadu, T., Fantahun, T. and Chanie, M. (2012) Small Ruminant Hydatidosis: Occurrence and Economic Importance in Addis Ababa Abattoir. Global Veterinaria. 8 (2): 160-167. 